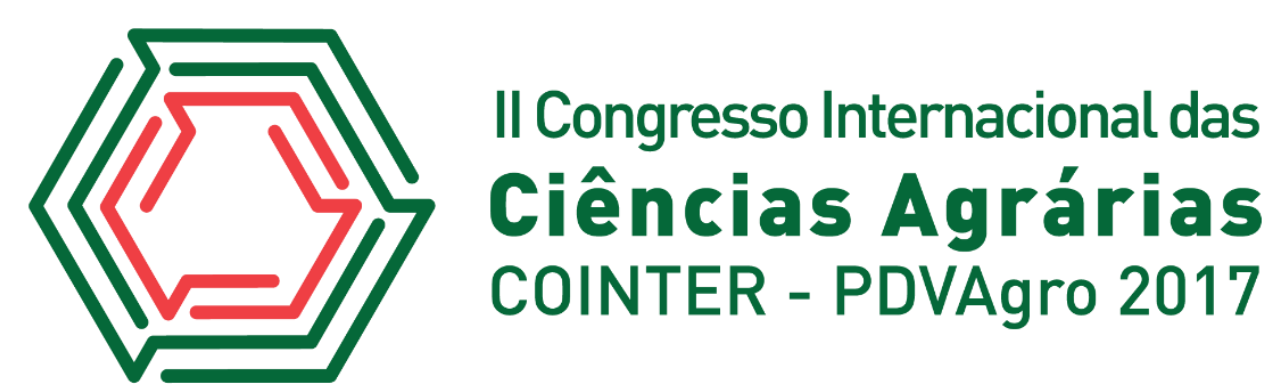

\title{
CARACTERIZAÇÃO E DIFERENCIAÇÃO DE ACESSOS DE CANA-DE-AÇÚCAR E ESPÉCIES RELACIONADAS POR MEIO DE DESCRITORES MORFOLÓGICOS
}

\author{
Apresentação: Pôster
}

Tassiano Maxwell Marinho Câmara ${ }^{1}$; Adriane Leite do Amaral ${ }^{2}$; Lizz Kezzy de Morais ${ }^{3}$; Herácliton de Éfeso da Silva ${ }^{4}$

\section{Introdução}

Uma das primeiras caracterizações utilizadas na diferenciação de germoplasma introduzido em bancos ativos (BAGs) é a morfológica. A caracterização morfológica fornece uma informação inicial sobre a variabilidade existente nas coleções biológicas. Outras vantagens desse tipo de caracterização são (Burle \& Oliveira, 2010): i) pode permitir uma fácil diferenciação entre fenótipos; ii) fornece uma medida de integridade genética dos acessos conservados; iii) fornece informações úteis para o manejo do germoplasma; iv) gera informações importantes para o uso do germoplasma em programas de melhoramento; v) possibilita a eliminação de duplicatas, reduzindo os custos de manutenção das coleções e bancos de germoplasma.

Em cana-de-açúcar o Ministério da Agricultura, por meio do Serviço Nacional de Proteção de Cultivares, publicou a portaria ${ }^{\circ} 1$ de 2 de março de 1998, que estabelece uma lista de descritores morfológicos para diferenciação de cultivares, além de orientações para condução de testes a campo de distinguibilidade, homogeneidade e estabilidade (Ministério da Agricultura, 1998).

A referida lista conta com 46 descritores com grande potencial para diferenciação de acessos de cana-de-açúcar e espécies relacionadas. Contudo, a aplicação de todos os descritores na diferenciação de acessos exige tempo, mão de obra e recursos, em geral, não disponíveis a contento.

\footnotetext{
${ }^{1}$ Doutor, Embrapa Tabuleiros Costeiros, tassiano.camara@embrapa.br

2 Doutora, Embrapa Tabuleiros Costeiros, adriane.amaral@embrapa.br

${ }^{3}$ Doutora, Embrapa Tabuleiros Costeiros, lizz.kezzy@embrapa.br

${ }^{4}$ Estudante de agronomia, Universidade Federal de Alagoas (UFAL), heracliton_efeso@outlook.com
} 
O presente trabalho teve por objetivo caracterizar acessos e avaliar o uso de descritores morfológicos na diferenciação de germoplasma de cana-de-açúcar e espécies relacionadas no banco ativo de germoplasma da Embrapa.

\section{Fundamentação Teórica}

A caracterização de germoplasma é uma estratégia importante na conservação, valoração e uso de recursos genéticos (Burle \& Oliveira, 2010). Em bancos ativos de germoplasma (BAGs) a disponibilização dessas informações tende a ampliar o intercâmbio de acessos, favorecendo a conservação dos recursos genéticos e o uso destes em programas de melhoramento para o desenvolvimento de cultivares com atributos mais favoráveis.

Em cana-de-açúcar essa caracterização é de grande importância para utilização dos recursos genéticos visto a alta variabilidade genética existente no gênero Saccharum e espécies relacionadas (denominado "Complexo Saccharum”) conservada nos BAGs (Henry \& Kole, 2010; Todd et al., 2014).

\section{Metodologia}

A pesquisa, de natureza qualitativa, foi conduzida no campo experimental da Embrapa Tabuleiros Costeiros (CPATC), localizado em Nossa Senhora das Dores, SE (10² $20^{\prime} \mathrm{S}$ e $37^{\circ}$ 10’ W). Na realização do trabalho foram utilizados doze acessos de cana-de-açúcar e espécies relacionadas (Saccharum sp, S. officinarum, S. robustum, S. spontaneum, Erianthus arundinaceus e Miscanthus sp.) pertencentes ao Banco Ativo de Germoplasma do Complexo Saccharum (BAGCana), mantido pelo CPATC.

Para a caracterização da diversidade morfológica dos acessos foi instalado, em novembro de 2015, um ensaio no delineamento de blocos ao acaso com três repetições e parcelas constituídas de três linhas de quatro metros, com espaçamento entre linhas de 1,5 m, sendo considerada área útil a linha central. $\mathrm{O}$ ensaio foi conduzido com irrigação e os tratos culturas realizados conforme necessidade da cultura.

A condução do ensaio e a caracterização da diversidade morfológica dos acessos foram realizadas conforme portaria $\mathrm{n}^{\circ}$, de 2 de março de 1998 do Ministério da Agricultura (Ministério da Agricultura, 1998). Para definir a expressão de cada característica foi considerada a moda obtida (resultado mais frequente) nas três repetições avaliadas. 


\section{Resultados e Discussões}

A diversidade morfológica presente nos acessos pertencentes ao BAGCana em relação a características relacionadas ao colmo é observada na Figura 1. Apesar do reduzido número de acessos avaliados constata-se a presença de variação morfológica para inúmeras características. Essa variação é função da grande diversidade genética existente no Complexo Saccharum, como relatado na literatura (JAMES, 2004; HENRY \& KOLE, 2010).

Figura 1. Diversidade morfológica em acessos de cana-de-açúcar e espécies relacionadas, pertencentes ao banco de germoplasma da Embrapa, localizado em Nossa Senhora das Dores - SE. A) Visão geral dos colmos; B) Detalhe da variação no comprimento do entrenó (setas vermelhas) e disposição dos entrenós do colmo em formato ziguezague (linha vermelha); C) Variação na largura de colmos; D) variação na diferença entre gemas; E) destaque o comprimento e intensidade da região cerosa. Fonte: Própria.

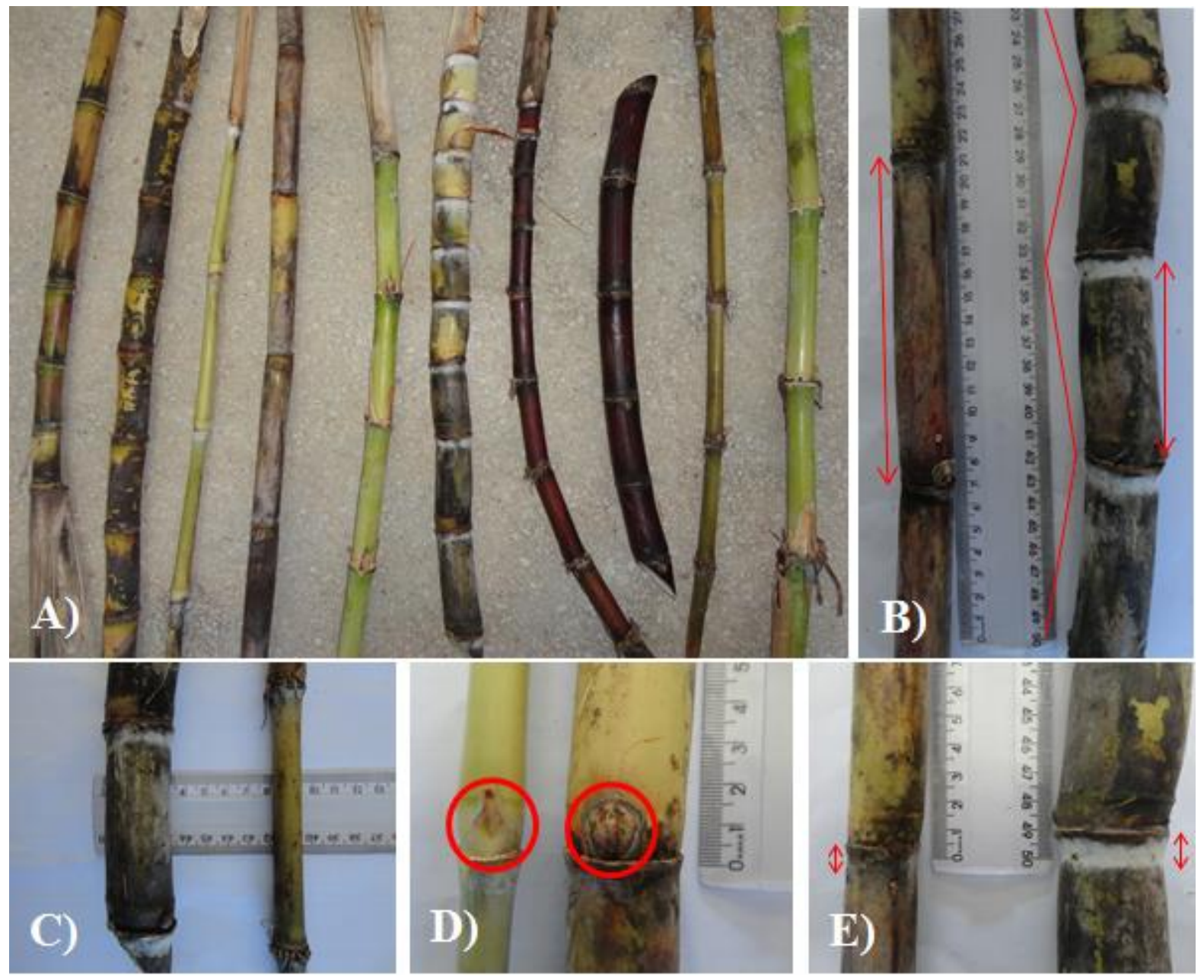

Em geral, os acessos apresentaram-se distintos entre si para a maioria dos descritores morfológicos, a exceção de genótipos como 117 e 120, com maior número de características 
coincidentes (Tabela 1). A presença de mais de uma classe fenotípica para todos os descritores avaliados contribuiu para a diferenciação dos acessos.

Tabela 1. Caracterização morfológica ${ }^{1 /}$ em $\operatorname{acessos}^{2 /}$ de cana-de-açúcar e espécies relacionadas. Nossa Senhora das Dores, SE. 2016. Fonte: Própria

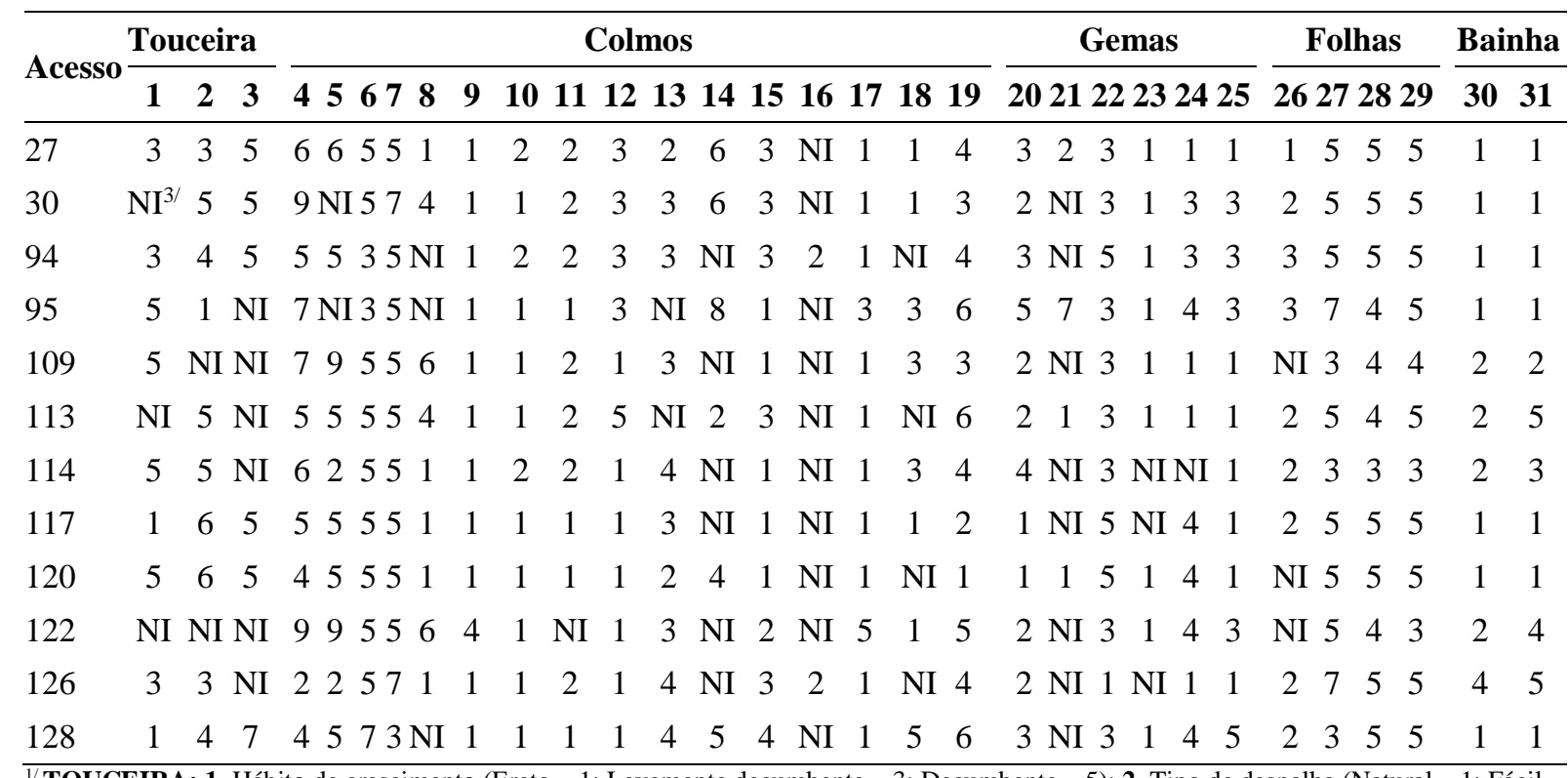

1/ TOUCEIRA: 1. Hábito de crescimento (Ereto - 1; Levemente decumbente - 3; Decumbente -5 ); 2 . Tipo de despalha (Natural - 1; Fácil 3; Média - 5; Difícil - 7); 3. Intensidade de perfilhamento (Baixa - 3; Média - 5; Alta - 7); COLMOS: 4. Cor dos entrenós ao sol (Branco verde - 1; Amarelo verde - 2; Amarelo roxo - 3; Verde - 4; Verde amarelo - 5; Verde roxo - 6; Roxo - 7; Roxo amarelo - 8; Roxo verde 9); 5. Cor dos entrenós sob a palha (Branco verde - 1; Amarelo verde - 2; Amarelo roxo - 3; Verde - 4; Verde amarelo - 5; Verde roxo - 6; Roxo - 7; Roxo amarelo - 8; Roxo verde - 9); ․ Comprimento dos entrenós (Curto - 3; Médio - 5; Longo - 7); 7. Diâmetro dos entrenós (Fino - 3; Médio - 5; Grosso - 7); 8. Formato de entrenó (Cilíndrico - 1; Tumescente - 2; Bobinado - 3; Conoidal - 4; Obconoidal - 5; Curvado - 6); 9. Tipos de rachaduras nos entrenós (Ausentes - 1; Rasas - 3; Profundas - 5); 10. Disposição dos entrenós no colmo em ziguezague (Ausente - 1; Suave - 2; Nítida - 3); 11. Aspecto dos entrenós (Liso - 1; Manchada - 2; Estriada - 3); 12. Canaleta da gema (Ausente - 1; Rasa - 3; Profunda - 5); 13. Quantidade de cera no entrenó (Ausente - 1; Pouca - 3; Muita - 5); 14. Cor do anel de crescimento do nó (Branco verde - 1; Amarelo verde - 2; Amarelo roxo - 3; Verde - 4; Verde amarelo - 5; Verde roxo - 6; Roxo - 7; Roxo amarelo - 8; Roxo verde - 9); 15. Saliência do anel de crescimento do nó (Pouca - 1; Média - 3; Muita - 5); 16. Cor do primórdio radicular sob a palha (Branco verde - 1; Amarelo verde - 2; Amarelo roxo - 3; Verde - 4; Verde amarelo - 5; Verde roxo - 6; Roxo - 7; Roxo amarelo - 8; Roxo verde - 9); 17. Enraizamento aéreo na zona radicular do nó (Ausente - 1; Pouco - 3; Médio - 5; Forte - 7); 18. Inserção da gema em relação à cicatriz foliar (Ausente - 1; Estreita - 3; Média - 5; Larga - 7); 19. Zona cerosa do nó (Ausente - 1; Pequena - 3; Regular - 5; Nítida - 7); GEMAS: 20. Saliência das gemas no nó (Pouca - 1; Média - 3; Muita - 5); 21. Tipo de gema (Triangular - 1; Ovalada - 2; Obovada - 3; Pentagonal - 4; Rombóide - 5; Redonda - 6; Oval - 7; Retangular - 8; Bicuda - 9); 22. Inserção da gema em relação ao anel de crescimento (Nunca ultrapassa - 1; Ocasionalmente ultrapassa - 2; Sempre ultrapassa - 3); 23. Posição do poro da gema (Apical - 1; Sub apical - 2); 24. Distribuição de pelos nas gemas (Ausentes - 1; Na base - 2; No ápice - 3; Em torno - 4); 25. Almofada da gema (Ausente - 1; Estreita - 3; Média - 5; Larga - 7); FOLHAS: 26. Arquitetura foliar (Ereta - 1; Pontas curvas - 2; Arqueadas - 3; Curvas na base - 4); 27. Largura do limbo (Estreito - 3; Médio - 5; Largo - 7); 28. Volume da copa foliar (Rala - 3; Regular - 5; Densa 7); 29. Tonalidade da copa foliar (Clara - 3; Intermediária - 5; Escura - 7); BAINHA: 30. Posição da pilosidade (Ausente - 1; Dorsal - 2; Lateral - 3; Ambos - 4); 31. Quantidade de pilosidade (Ausente - 1; Pouco - 3; Regular - 5; Muita - 7). Para cada característica, valores presentes na tabela mas não descrito acima correspondem a resultados intermediários entre duas classes fenotípicas;

${ }_{2 /} 27$ e 30 - Saccharum sp.; 94 e 109 - Saccharum robustum; 95 - Saccharum híbrido; 113 e 114 -Miscanthus sp.; 117 e 120 - Erianthus arundinaceus; 122 e 126 - Saccharum officinarum; 128 - Saccharum spontaneum;

${ }^{3 /} \mathrm{NI}$ - classe fenotípica não identificada.

Pelos dados apresentados na Tabela 1 constata-se que o uso de poucos descritores morfológicos (por exemplo, cor dos entrenós ao sol, zona cerosa do nó e saliência das gemas no nó) já seria suficiente para diferenciar os 12 genótipos avaliados, evidenciando a aplicabilidade do uso desse tipo de caracterização na distinção de germoplasma do "Complexo Saccharum". 
Contudo, para algumas características, como cor do primórdio radicular sob a palha $\left(n^{\circ}\right.$. 16), houve maior dificuldade na identificação da classe fenotípica (as avaliações realizadas nas três repetições do ensaio diferiram entre si, não sendo identificado uma moda). O maior número de variações fenotípicas, como aquelas relacionadas a coloração, associado a avaliação de características de tamanho reduzido, dificultaram a definição da classe fenotípica nas avaliações à campo.

\section{Conclusões}

Acessos conservados do BAGCana apresentam variação para descritores morfológicos;

Os descritores morfológicos são eficientes na diferenciação de acessos do Banco Ativo de Germoplasma.

\section{Referências}

BURLE, M.L.; OLIVEIRA, M.S.P. Manual de curadores de germoplasma - Vegetal: Caracterização morfológica. Brasília, DF: Embrapa Recursos Genéticos e Biotecnologia, 2010. 15p. (Documentos 312).

HENRY, R.J.; KOLE, C. Genetics, genomics and breeding of sugarcane. Enfield: Science Publishers, 2010.

JAMES, G. An Introduction to Sugarcane. In: James, G. (Ed.) - Sugarcane. 2. Ed. Oxford: Blackwell Science Ltd, p.1-19, 2004.

MINISTÉRIO DA AGRICULTURA. Portaria ${ }^{\circ} 1$ de 2 de março de 1998. Divulga, para fins de abertura de pedido de proteção de cultivares, a espécie vegetal cana-de-açúcar, cujos descritores mínimos estão definidos na forma do Anexo 1 desta Portaria. Diário Oficial, Brasília, 5 de março de 1998. Seção I, p. 95-98.

TODD, J.; WANG, J.; GLAZ, B.; SOOD, S.; NAYAK, S.N.; GLYNN, N.C.; GUTIERREZ, O.A.; KUHN, D.N. Phenotypic characterization of the Miami World Collection of sugarcane (Saccharum spp.) and related grasses for selecting a representative core. Genetic Resources and Crop Evolution. v. 61, p.1581-1596, 2014. 